\title{
A Study on the behaviour of Aluminium alloy (LM13) reinforced with $\mathrm{NanoZrO}_{2}$ Particulate
}

\author{
Sumod Daniel, Dr .G.Harish \\ ${ }^{1 .}$ Designation: Associate professor ,Department of mechanical engineering. Organisation; Bangalore college of \\ engineering and technology Chandapura,near heelalige railway station, Bangalore-560099 Karnataka. \\ ${ }^{2}$ Designation: Associate professor, Department of mechanical engineering. Organisation; University college of \\ engineering . KR circle ,Bangalore-560001. Karnataka.
}

\begin{abstract}
The present work analyses the characteristic behaviour of the Aluminium alloy (LM13) reinforced with nano-zro 2 particulates by Stir Casting technique . The experimentation is carried out by distribution nano$\mathrm{ZrO}_{2}$ particles of size varying from $50-80 \mathrm{~nm}$ and quantity ranging from $2-10 \mathrm{wt} . \%$.

The composite synthesized is analysed and evaluated in various aspects of strength ,ductility, porosity and hardness by adapting microstructural, mechanical and fractographic techniques and it is arrived that the Nano composite developed has significantly improved strength, hardness, retains residual porosity while compromising slightly with of the resultant composite. The $\mathrm{Al}-\mathrm{NanoZrO}_{2}$ composite thus synthesised displays a significantly reduced Electrical Resistivity and Thermal conductivity.
\end{abstract}

Keyword: - Al (LM13) metal matrix, Microstructural, Nano-ZrO $\mathrm{O}_{2}$ particulate.stir casting.

\section{INTRODUCTION:}

With the continued technological advancement in aeronautics, demand for advanced pneumatic components for ultra high end applications is on the rise.[1].Apart from aeronautics, the demand for such materials are also coming from automobiles and electronics sector in which presently used materials such as plastics are likely desired to be replaced by efficient alternates [2].The $\mathrm{Al}($ aluminium) metal matrix alloy structural materials ushered in a revolution in the last decade into the field of automobile engineering by enabling manufacture of light weight body parts and components which significantly reduced fuel consumption in addition to improving the strength of the components and also addressing various concerns on environmental safety and security grounds[3,4].improvising the advantageous abilities of Al matrix alloy by fine tuning the properties of strength and hardness of the alloy is the need of the hour since global demand for high efficiency $\mathrm{Al}$ matrix alloy material is rising exponentially[5].comprehensive research into the fabrication of the alloy is being carried out in order to address the shortfalls in it's mechanical properties which imposes an adverse effect in automobile and aeronautical applications and products.[6,7].An exploration into the contemporary research indicates that extensive research is being carried out to overcome the limitations of $\mathrm{Al}$ alloy based metal matrix composites(MMC's) such as to overcome the greater coefficient of friction values resulting due to the abrasive act of the dispersoids in the long run thereby significantly increasing the wear on the contact surface.[8-12]. However it is observed that little effort has been made into studying the characteristic behaviour of an $\mathrm{Al}$ alloy based MMC reinforced with nanoZrO 2 particulate dispersion.[13]. This research primarily aims to synthesise an $\mathrm{Al}$ alloy based composite reinforced with nanoZrO $\mathrm{Zr}_{2}$ particulates using Stir Casting technique followed by hot extrusion [14]. The composite material developed is studied and analysed in microstructural, mechanical, fractography, thermal and electrical aspects so as to deduce the effect of the nanoZrO $\mathrm{Zr}_{2}$ particulatesdispersed in standard LM13 Al alloy by increasing the content of Nano particulates added in a step by step manner.

\section{EXPERIMENTAL}

In this research, the Stir Casting technique is used to disperse the nanoZrO $\mathrm{Zr}_{2}$ particulates in $\mathrm{Al}$ Alloy (LM 13). The chemical composition of the $\mathrm{Al}$ alloy involves the following combination of metals (in wt \%): $\mathrm{Zn}$ - 0.5, $\mathrm{Mg}-1.4, \mathrm{Si}-1.2, \mathrm{Ni}-1.5, \mathrm{Fe}-1.0, \mathrm{Mn}-0.5$ and $\mathrm{Al}-$ bal. The size of the nanoZrO $\mathrm{Zr}_{2}$ particulates ranges between $50 \mathrm{~nm}$ to $80 \mathrm{~nm}$ and the quantity added ranges between $2 \mathrm{wt} \%$ to $10 \mathrm{wt} \%$ with an increase of $2 \mathrm{wt} \%$ in every step.The synthesis of $\mathrm{NanoZrO}_{2}$ reinforced $\mathrm{Al}$ composite Containingfive different wt $\%$ of nanoZrO${ }_{2}$ reinforcementinvolves producing a melt of the selected matrix material, followed by the introduction of a reinforcing material into the melt, obtaining asuitable dispersion through stirring. This is followed by desired distribution of the reinforcement and subsequent solidification of the melt. To achieve higher particle content in the cast composite the melt temperature is maintained with the partially solid range of the alloy which is called compact processing. This involves heating of the $\mathrm{Al}$ alloy in a alumina crucible upto $735^{\circ} \mathrm{c}$ using resistance furnace and addition of nanoZrO${ }_{2}$ reinforcement which is alreadypre heated to $250^{\circ} \mathrm{c}$ by constant stirring enabled 
by an impeller rotated at $425 \mathrm{rpm}$ so that a vortex is created to get a uniform reinforcement of the nanoZrO particulates in the $\mathrm{Al}$ (LM 13) alloy metal matrix. In the second step, the $\mathrm{Al}$ (LM 13) metal matrix dispersed with nanoZrO $\mathrm{Zr}_{2}$ particulates is extruded in a hydraulic press at $255^{\circ} \mathrm{c}$. The properties of the nanoZrO reinforcement synthesised is given in table1.

Table 1: Properties of the synthesised nanoZrO $\mathrm{Zr}_{2}$ reinforcement

\begin{tabular}{|l|l|}
\hline Property & Value \\
\hline Density & $8.2 \mathrm{gm} / \mathrm{cm}^{3}$ \\
\hline MeltingPoint & $1860^{\circ} \mathrm{c}$ \\
\hline UTS & $428 \mathrm{mpa}$ \\
\hline VHN & 151 \\
\hline Young's modulus & $97 \mathrm{Gpa}$ \\
\hline
\end{tabular}

Microstructural characteristics of the polished Al - NMMC specimens are studied using Olympus metallographic microscope. Fractured surfaces of the Al - NMMC are analysed with the help of HITACHI S4100 field emission scanning electron microscope. Vickers micro Hardness measurements are made using Digital Rockwell hardness Tester adopting ASTM E18-94 standard. Tension tests are performed using DutronDigital Tensile Testing machine adopting ASTM E8M-01 standard on AFS standard Tensometer specimens. Fracture toughness Tests are conducted using a closed loop Instron Servo hydraulic material testing system which involves 3 point bend testing of machined specimen precracked by fatigue. Thermal conductivity and electrical resistance are analysed using a comparative method.

\section{RESULTS AND DISCUSSION}

The integrated $\mathrm{Al}$ - nanoZro $\mathrm{rotal}_{2}$ matrix composite synthesised by employing Stir casting technique and subsequent hot extrusion by hydraulic press yielded better results in terms of retaining the microporosity of the composite, agglomeration and distribution of the nanoZro ${ }_{2}$ particulates over the Al metal matrix thereby producing a sound casting since the technique involves optimum conditions prevailing during the melt, processing, dispersion, deposition and solidification. The resultant NMMC establishes the feasibility of Stir Casting followed hot extrusion technique as a viable, economical and better fabrication technique in the synthesis of nanoZ $\mathrm{ro}_{2}$ metal matrix composite.

\subsection{Micro structural Analysis:}

Micro structural analysis of the $\mathrm{Al}-$ nanoZro $\mathrm{ro}_{2}$ metal matrix composite is performed studying the aspect of distribution of nanoZro $\mathrm{Zn}_{2}$ particulates over the base $\mathrm{Al}$ alloy metal matrix and integral bonding of the reinforced metal matrix. The analysis revealed the following results:

1. The NMMC cast synthesised, shows uniform distribution of reinforcement with minimal cluster formation of extruded Nano composites thus providing a smoother cast.

2. The cast exhibits better integrated bonding between the nanoZro $\mathrm{Hr}_{2}$ reinforcement and $\mathrm{Al}$ alloy metal matrix thus yielding a refined grain pattern in the composite thereby minimizing porosity.

The above achievement in the micro structural front is attributed to the Methodology adopted for fabrication of the composite.

Metallographic studies conducted on the samples of NMMC reveals the fact that the reinforcement and the metal matrix have got blended optimally. This optimal integration is because of the capability of the nanoZro ${ }_{2}$ particulates to combine with the $\mathrm{Al}$ metal matrix during the process of solidification of the cast with minimal grain growth during recrystallization.

The fractured surface of the end cast of reinforcement and Al Metal matrix is analysed to study the debonding aspects of the nanoZro 2 particulate- metal matrix interface with the help of a scanning electron microscope HITACHI S4100. The results confirmed of the non-presence of microspores in the contact points of particulate and matrix or any abnormal shrinkage cavity thus it is concluded that the $\mathrm{Al}$ - nanoZro ${ }_{2} \mathrm{MMC}$ cast is free from any defects in the micro structural front.

\subsection{Mechanical Properties:}


A Study on the behaviour of Aluminium alloy (LM13) reinforced with $\mathrm{NanoZrO}_{2}$ Particulate

Table -2: Mechanical Properties of Al-Nano $\mathrm{ZrO}_{2}$ MetalMatrix Composite

\begin{tabular}{|l|l|l|l|l|}
\hline & \multicolumn{2}{l|}{} \\
\hline $\mathrm{ZrO}_{2}(\mathrm{wt} \%)$ & $\mathrm{HV}$ & $0.2 \% \mathrm{YS}(\mathrm{MPa})$ & UTS(MPa) & Ductility(\%) \\
\hline 2 & 101 & 124 & 230 & 7.4 \\
\hline 4 & 108 & 132 & 248 & 5.8 \\
\hline 6 & 119 & 158 & 257 & 5.0 \\
\hline 8 & 128 & 183 & 262 & 4.2 \\
\hline 10 & 124 & 171 & 258 & 3.5 \\
\hline Matrixalloy(LM13) & 90 & 120 & 170 & 11 \\
\hline
\end{tabular}

The mechanical properties of the $\mathrm{Al}-\mathrm{Nano} \mathrm{ZrO}_{2} \mathrm{MMC}$ were studied toensure the hardness and strength of the composite and the results are discussed as follows:

(i) Micro hardness tests conducted on the extruded NMMC samples indicated an increasing rate of hardness with increase in the quantity of $\mathrm{Nano} \mathrm{ZrO}_{2}$ reinforcement and the value peaked at $8 \mathrm{wt} \%$ (see Table 2).

(ii) The value of hardness of NMMC peaks at $8 \mathrm{wt} \%$ at 128 (see Table 2)and then started to decline with further addition of another $2 \mathrm{wt} \%$ (i.e.)at $10 \mathrm{wt} \%$ of reinforcement. The increase in hardness of the NMMC under study in primarily attributed to the harder Nano $\mathrm{ZrO}_{2}$ particulates in the matrix which has solidified and recrystallized with minimum porosity and greater interfacial bonding with better grain refinement.

(iii) Due to increased grain refinement, there is an increase in the grain boundary area which under applied stress obstructs the dislocation of the composite grain ending up in pile up in the grain boundaries [16]. This in turn increases the strength of the NMMC.

(iv) The temperature tensile test conducted indicatesthat the tensile strength of the $\mathrm{Al}-\mathrm{Nano}_{\mathrm{ZrO}} \mathrm{MMC}$ has significantly increased which is ascertained from the $0.2 \% \mathrm{YS}$ and UTS values. This increase in tensile strength is due to effective transfer of applied tensile load to the uniformly distributed well bonded reinforcement [15]. The Nano $\mathrm{ZrO}_{2}$ particulates with a greater aspect ratio contribute to the buildingof thermal stress in the reinforcement metal interface resulting due to production of difference in co-efficient of thermal expansion between the two surfaces which also considerably increase the tensile strength.

(v) The only counterproductive effect of the reinforcement in the Al metal matrix is the ductility of the composite which is because of an induced change of the composites' fracture mode from ductile intergranular to cleavage.

\subsection{Fracture toughness}

Table -3

\begin{tabular}{|l|l|}
\hline $\mathrm{ZrO}_{2}($ wt.\%) & Fracture toughness $(\mathrm{Mpa} \sqrt{\mathrm{m}})$ \\
\hline 2 & 11.5 \\
\hline 4 & 13.8 \\
\hline 6 & 15.1 \\
\hline 8 & 15.5 \\
\hline 10 & 14.0 \\
\hline
\end{tabular}

The Al-Nano $\mathrm{ZrO}_{2} \mathrm{MMC}$ samples are tested for Fracture toughness that Determines the hardness of the composite and in turn stands testimony to the durability of the end cast thus fabricated.The test results concluded that Fracture toughness of the composite increased phenomenally with addition of reinforcement successively and reached peak value of $15.5 \mathrm{Mpa} \sqrt{\mathrm{m}}$ for $8 \mathrm{wt} \%$ addition of reinforcement to the $\mathrm{Al}$ alloy and then got reduced for $10 \mathrm{wt} \%$ to 14.0 (See table-3). Hence the study establishes the fact that the reinforced composite gains more strength due to the addition of reinforcement since the addition makes $\mathrm{Al}$ metal matrix more denser than the monolithic Al alloy (LM13).

A comparative study on fracture surface analysis of FCC structured alloy Samplesand the synthesised NMMC samples was conducted to probe the ductility of the two alloys and theresults are as follows: In the FCC structured $\mathrm{Al}$ alloy the fractured particles of the materials are fine And posses shallow depressions thus making the fracture ductile. 


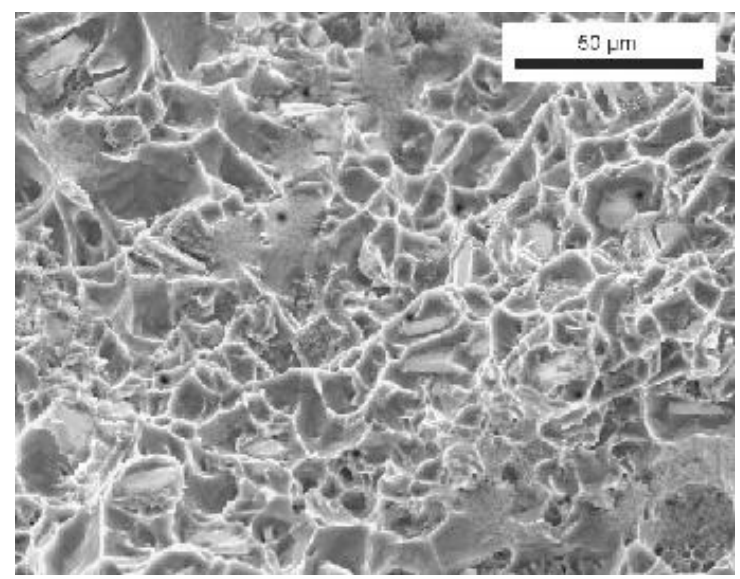

Fig.1. SEM Fractogrphic image of Al Metal Matrix Alloy (LM13)

However in case of NMMC's (See Fig.2) Containing $8 \mathrm{wt} \%$ of reinforcement, the fracture mode is found to be of cleavage type due to excessive distribution of $\mathrm{ZrO}_{2}$ particulates. These particulates under stress are prone to fracture thus reducing the ductility of the composite while on the other hand increasing hardness and strength of the composite considerably.

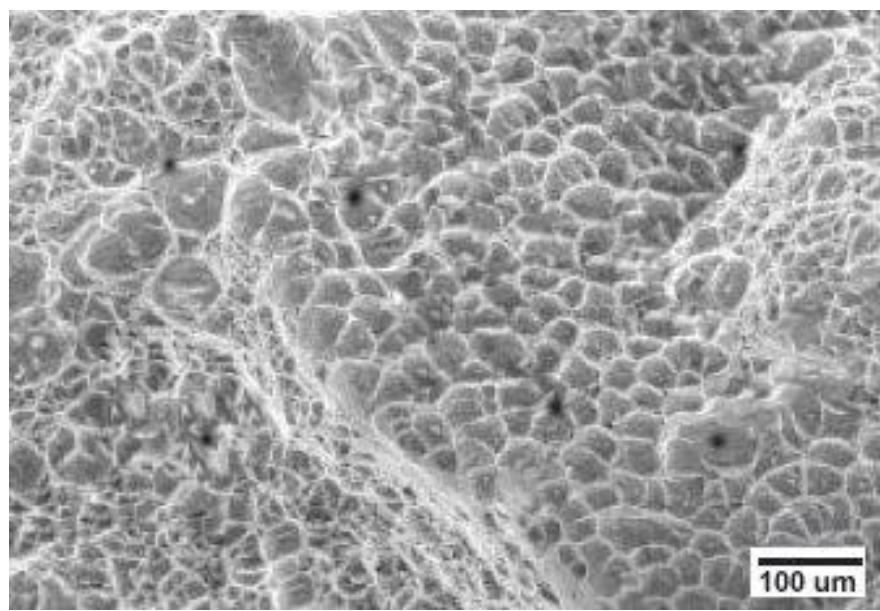

Fig.2. SEM Fractographic image of Al Metal matrix reinforced with $8 \mathrm{wt} \%$ of Nano $-\mathrm{ZrO}_{2}$

\subsection{Thermal and Electrical Properties:}

Table -4

\begin{tabular}{|l|l|l|}
\hline \multicolumn{2}{|c|}{ Properties } \\
\hline $\begin{array}{c}\mathrm{ZrO}_{2} \\
(\mathrm{Wt} . \%)\end{array}$ & $\begin{array}{c}\text { Thermal Conductity } \\
(\mathrm{W} / \mathrm{mk})\end{array}$ & $\begin{array}{c}\text { Electrical Resistivity } \\
(\mu \Omega-\mathrm{m})\end{array}$ \\
\hline 2 & 140 & 3.1 \\
\hline 4 & 134 & 2.8 \\
\hline 6 & 128 & 2.5 \\
\hline 8 & 120 & 2.0 \\
\hline 10 & 116 & 1.8 \\
\hline $\mathrm{Al}$ alloy (LM13) & 166 & 3.65 \\
\hline
\end{tabular}

With respect to thermal conductivity,unlike the matrix alloy which has a higher thermal conductivity, the $\mathrm{Al}$ Nano $\mathrm{ZrO}_{2} \mathrm{MMC}$ synthesised in this work shows reduced thermal conductivity which could be inferred from the table -4 . Thermal conductivity of Al metal matrix significantly decreases with addition of Nano $\mathrm{ZrO}_{2}$ particulates attaining the lowest thermal conductivity for $10 \mathrm{wt} \%$ addition of Nano $\mathrm{ZrO}_{2}$ particulates. This reduction is attributed to the fact that increasing $\mathrm{ZrO}_{2}$ particulate content possibly leading to increasing in phonon scattering which reduced thermal conductivity considerably. 
In respect of the property of electrical resistivity the NMMC reinforced Al metal exhibits a significantly reducing pattern of electrical resistivity with successive addition of reinforcement of $\mathrm{Nano} \mathrm{ZrO}_{2}$ for the $\mathrm{ZrO}_{2}$ particulate itself has a lower electrical resistivity within the range between 0.052 to $0.23 \mu \Omega-\mathrm{m}$.

\section{CONCLUSION}

The Al Nano- $\mathrm{ZrO}_{2}$ metal matrix composite synthesised by Stir Casting technique exhibits the following characteristics:

The composite under micro structural analysis displayed a smooth cast with fine grained blending of metal alloy and reinforcement with fair distribution of $\mathrm{Nano}-\mathrm{ZrO}_{2}$ particulates with minimal porosity.

The NMMC exhibits better strength and hardness and improved tensile strength thereby improving the overall mechanical properties of the metal matrix slightly compromising the ductility due to change in the mode of fracture toughness which is revealed from fractographic analysis.

Finally, it is concluded in the part of the electrical and thermal properties that electrical resistivity and thermal conductivity of $\mathrm{Al}$ metal matrix is inversely proportional to the addition of reinforcement with $\mathrm{Nano}-\mathrm{ZrO}_{2}$ particulates.

\section{REFERENCES}

[1] M.M. Opeka,I.G.Talmy, J.A.Zaykoki,J.Mater.Sci.32(2004)5887-5894.

[2] A.Luo,Metall.Mater.Trans.26(1995)2445-2453.

[3] R.A.Saravanan,M.K.Surappa,Mater.Sci.Eng. A108(2000)276-285.

[4] S.F.Hassan,J.Gupta,J.Mater.Sci.37(2002)2467-2477.

[5] S.Awasthi,J.L.Wood,Adv.Ceram.Mater.(1988)3449-3458.

[6] M.O.Lai,J.Mater.Sci.35(2000)2155-2169.

[7] C.R.Wang,J.M.Yang,Mater.Chem.Phys.74(2002)272 286.

[8] B. Venkataraman, G. Sundararajan, Acta Mater. 44(1996) 461.

[9] S. Murphy, A. Wang, Mater. Sci. Engg.A 147 (1991)211

[10] S. Wilson, A.T. Alpas, Wear 212 (1997) 41

[11] D.P. Mondal, S. Das, R.N. Rao, M. Singh, Mater. Sci. Eng. A 402 (2005) 307-319.H. Mifune, Wear 213 (1997) 175.

[12] R. Chen, A. Iwabuchi, T. Shimizu, H. Mifune, Wear 213 (1997) 17

[13] D.J.Lloyd,Int.Mater.Rev.39(1994)1-10.

[14] Hashim J, Looney L and Hashmi M S J, Metal Matrix Composites Production bythe Stir Casting Method, Proceeding of the International Conference on Advances inMaterials and Processing Technologies, Iniversidade do Minho, Portugal, July 1997 pp 1-8

[15] T.S. Srinivasan, M. Gupta, J. Materi. Eng. Perform. 8 (1999) 473-489.

[16] R.E. Reed Hill, Physical Metallurgy Principles, 2nd ed., D. Van Nostrand Com-pany, UK, 1964, 56-69.

[17] C. Garcia, N. Ordas, J. Nucl. Mater. 30 (2002) 1282-1294. 